\title{
Prominent middle genicular artery
}

\author{
Kevin M. Garrett • Robert J. Fleck Jr.
}

Received: 17 June 2010 /Revised: 10 September 2010 / Accepted: 21 September 2010 / Published online: 10 October 2010

(C) Springer-Verlag 2010

A 17-year-old boy underwent MRI for knee trauma, revealing a torn medial meniscus (Fig. 1). Additionally, an unidentified linear structure was demonstrated coursing through knee joint space. This was further evaluated with MR angiography, revealing it to be arterial in origin (Fig. 2). This vessel followed the expected course of the middle genicular artery. Typically the middle genicular artery is small and tortuous [1]. This boy's middle genicular artery was more conspicuous because of its generous diameter and relatively straight course in congruity with the plane of imaging.

The middle genicular artery originates from the popliteal artery, enters the posterior joint capsule and

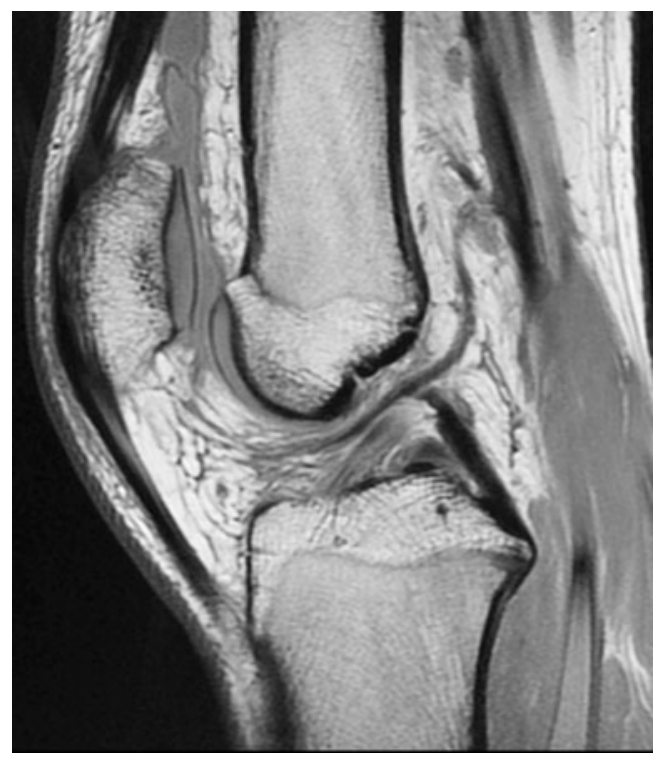

Fig. 1 Sagittal proton-density MRI

K. M. Garrett • R. J. Fleck Jr. $(\bowtie)$

Department of Radiology, Cincinnati Children's Hospital Medical Center,

3333 Burnet Ave.,

Cincinnati, OH 45229, USA

e-mail: Robert.Fleck@cchmc.org

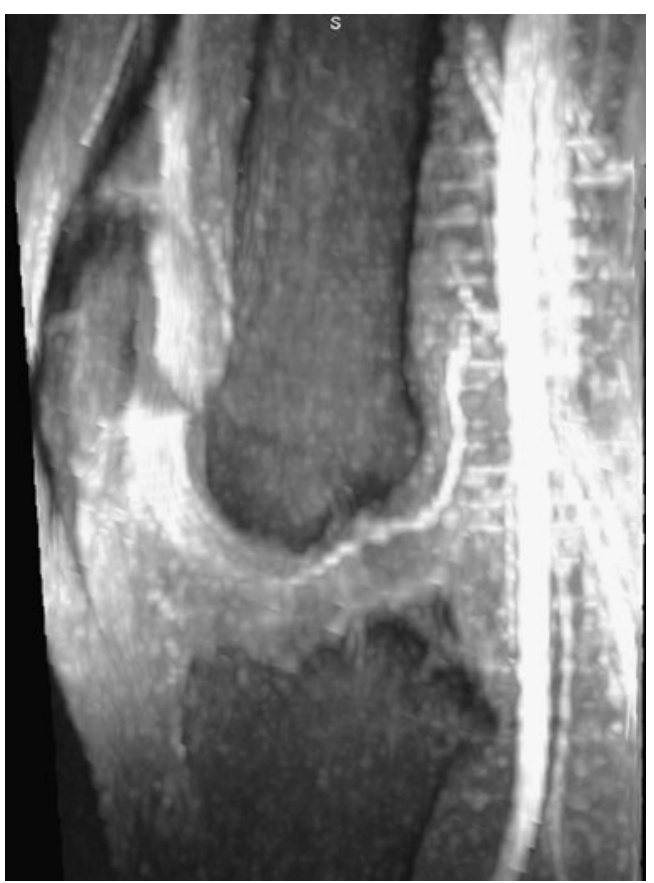

Fig. 2 Reconstructed 2D time-of-flight MR MIP angiogram with inferior saturation pulse

courses through the joint space, providing blood supply to the anterior and posterior cruciate ligaments [1]. An artery of this prominence should be described, given its potential for complication during arthroscopic knee procedures $[1,2]$.

\section{References}

1. Salaria H, Atkinson R (2008) Anatomic study of the middle genicular artery. J Orthop Surg 16:47-49

2. Aldridge JM 3rd, Weaver JP, Mallon WJ (2002) Avulsion of the middle genicular artery: a previously unreported complication of anterior cruciate ligament repair. A case report. Am J Sports Med $30: 748-750$ 